\title{
SEM contrast of semi-insulating compound materials
}

\author{
H.-J. Fitting ${ }^{1}$ and J. Z. Kovacs ${ }^{2}$ \\ ${ }^{1}$ University of Rostock, Institute of Physics, Universitaetsplatz 3, D-18051 Rostock, Germany \\ ${ }^{2}$ Hamburg University of Technology, Institute for Optical and Electronic Materials, \\ Eissendorfer Str. 38, D-21073 Hamburg, Germany
}

The invention of the scanning electron microscopy (SEM) is concerned with Max Knoll in Berlin 1935 published in [1]. Even in this first paper charging phenomena of insulating samples are described too. In recent years the electron beam irradiation and charge injection in insulating samples have been described by means of an electron-hole flight-drift model (FDM) implemented by a computer simulation [2-4]. Ballistic scattering and transport of secondary electrons and holes is followed by drift, possible recombination and/or trapping and detrapping. In this context special surface layers have been installed to investigate charging prevention [3] and to simulate surface leakage currents, [4]. For bulk full insulating samples the time dependent secondary electron emission rate $\sigma(t)$ and surface potential $V_{0}(t)$ approach the final stationary state under the condition $j(x, t)=$ const $=0$ and $\sigma=1$. But in semiconducting and semi-insulating samples these relations are not fulfilled. In this context we want to remember to an old resistance model, e.g. quoted in [5]. There a certain sample resistance $R_{i}$ controls a partial charging of the semiconducting or semiinsulating sample as demonstrated in Fig.1. The actual landing energy $\mathrm{E}_{\mathrm{v}}=\mathrm{eU}_{\mathrm{v}}$ of the electron beam is enhanced or diminished by the surface potential $\mathrm{U}_{\mathrm{s}} \lessgtr 0$ :

$$
\mathrm{E}_{\mathrm{v}}=\mathrm{e}_{0} \mathrm{U}_{\mathrm{v}}=\mathrm{e}_{0}\left(\mathrm{U}_{0}+\mathrm{U}_{\mathrm{s}}\right)=\mathrm{E}_{0}+\mathrm{e}_{0}(\sigma-1) \mathrm{i}_{0} \mathrm{R}_{\mathrm{i}}
$$

The interceptions of the resistance lines $\sigma\left(\mathrm{U}_{0}, \mathrm{U}_{\mathrm{v}} \mathrm{R}_{\mathrm{i}}\right)$ with the SE yield curve $\sigma\left(\mathrm{E}_{\mathrm{v}}=\mathrm{E}_{0}\right)$ result in the actual state of charging $\left(\mathrm{U}_{\mathrm{s}}\right)$ and SE yield $\sigma\left(\mathrm{E}_{\mathrm{v}}\right)$. So we see that the $\left(\sigma_{0}=1\right)$-energies $\mathrm{E}_{0}^{\mathrm{I}}$ and $\mathrm{E}_{0}^{\mathrm{II}}$ are for the first value labile and for the second one stable (even attractive) as mostly used in simple charging models for full insulating samples $R_{i}=\infty$. Hence for conducting samples $R_{i}=0$ we get no charging and $\mathrm{E}_{\mathrm{v}}=\mathrm{E}_{0}$.

In Fig.2 an element contrast around the first $(\sigma=1)$ point $\mathrm{E}_{0} \lessgtr \mathrm{E}_{0}^{\mathrm{I}}$ (see Fig. 1 ) is demonstrated. The metal $(\mathrm{Pb})$ islands appear darker than the silicon substrate for very low electron beam energies $\mathrm{E}_{0}=5$ $\mathrm{eV}<\mathrm{E}_{0}^{\mathrm{I}}$ with a gradual contrast inversion to $\mathrm{E}_{0}=378 \mathrm{eV}>\mathrm{E}_{0}^{\mathrm{I}}$, see [6]. In Fig.3 a contrast inversion appears from the initial uncharged state (pure element contrast) to the charged-up insulating epoxy resin matrix with imbedded carbon nanotubes (CNT), [7]. The same sample shows an energydependent contrast inversion around $\mathrm{E}_{0}^{\mathrm{II}}$, shown in Fig.3.

\section{References}

[1] M. Knoll, Zeitschrift f. Technische Physik 11 (1935) 467-475.

[2] X. Meyza, D. Goeuriot, C. Guerret-Piécourt, Tréheux, H.-J. Fitting, JAP 8 (2003) 5384-5392.

[3] M. Touzin, D. Goeuriot, C. Guerret-Piécourt, et al., JAP 99 (2006) 114110.

[4] N. Cornet, D. Goeuriot, C. Guerret-Piécourt, et al., JAP 103 (2008) 064110.

[5] I. M. Bronshtein, B. S. Fraiman, "Secondary Electron Emission” (russ.), Naúka, Moscow 1969.

[6] I. Muellerova, Scanning 23 (2001) 379-394.

[7] J. Z. Kovacs, K. Andresen, J. R. Pauls, C. P. Garcia, et al., Carbon 45 (2007) 1279-1288. 


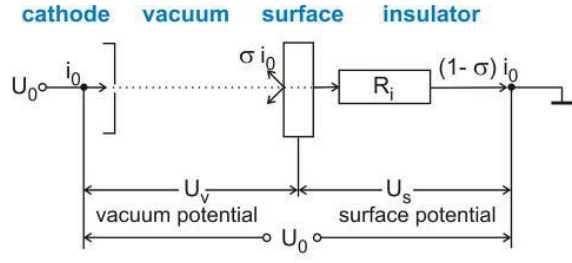

$$
\begin{array}{r}
U_{0}=U_{v}+U_{s} \\
\sigma=1-\frac{U_{0}-U_{v}}{i_{0} R_{i}}
\end{array}
$$

resistance lines

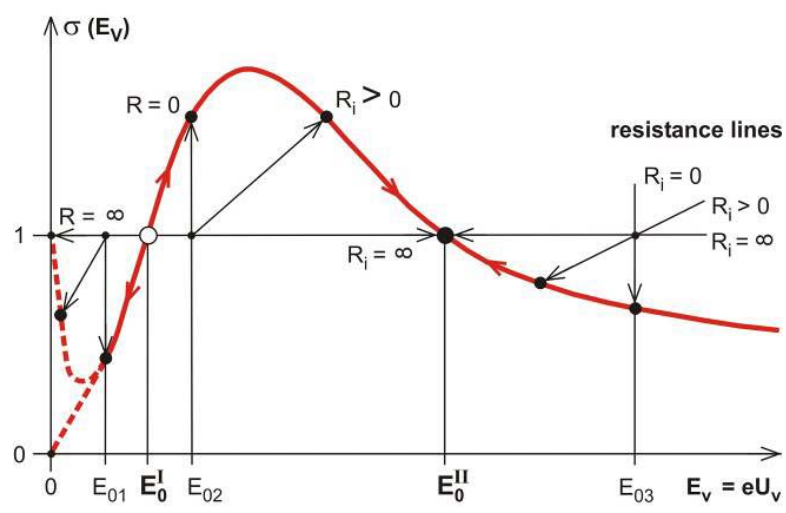

PE landing energy

Fig.1 SEE resistance model for semiconductors and insulators; $\mathrm{R}_{\mathrm{i}}$ internal sample resistance.
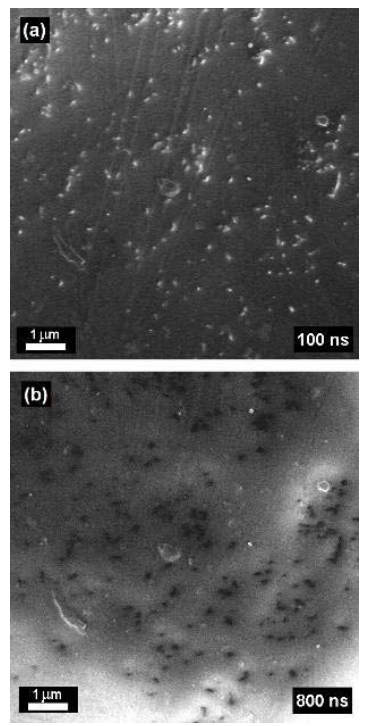

Fig. 3 Time-dependent charge contrast inversion from short (100 ns above) to longer irradiation times $\mathrm{t}=800 \mathrm{~ns}$ (below) of CNT in epoxy resin; $\mathrm{E}_{0}=0.6 \mathrm{keV}$.

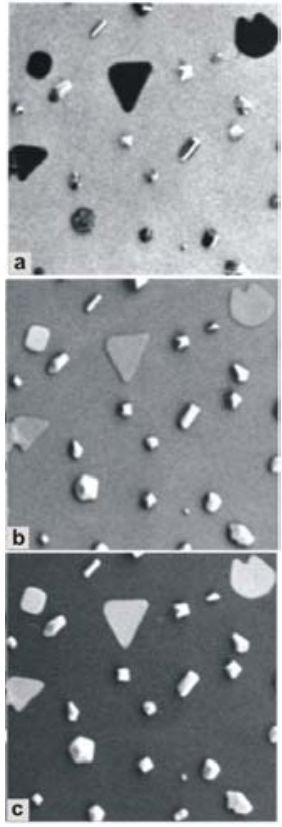

Fig.2 Element contrast inversion of $\mathrm{Pb}$ islands on $\mathrm{Si}$ substrate at very low beam energies $\mathrm{E}_{0} \lessgtr \mathrm{E}_{0}^{\mathrm{I}}$ : $\mathrm{E}_{0}=5 \mathrm{eV}(\mathrm{a}) ; 42.5 \mathrm{eV}$ (b); $378 \mathrm{eV}$ (c), with courtesy of I. Muellerova (ISI Brno) [6].

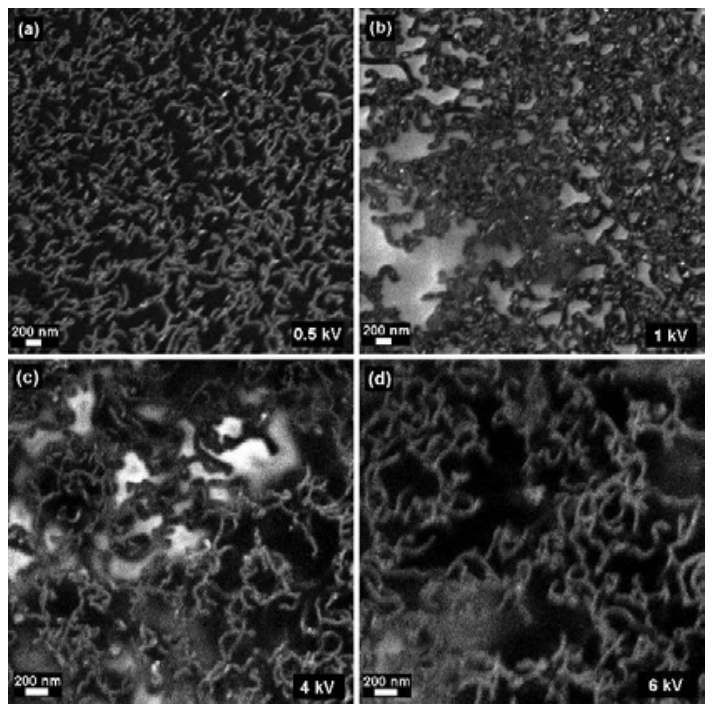

Fig. 4 Energy-dependent charge contrast inversion of CNT in epoxy resin around $\mathrm{E}_{0} \lessgtr \mathrm{E}_{0}^{\mathrm{II}}$, $\mathrm{E}_{0}=0.5 ; 1.0 ; 4.0 ; 6.0 \mathrm{keV}$. 